\title{
Geospatial analysis of severe road traffic accidents in Singapore in 2013-2014
}

\author{
Choon Peng Jeremy $\underline{W e e}^{1}$, MBBS, MSc, Daniel Xin-Peng $\underline{\mathrm{He}}^{1}, \mathrm{MD}, \mathrm{BSc}$, Wah $\underline{W i n}^{1}, \mathrm{MBBS}, \mathrm{MPH}$,
} Marcus Eng Hock Ong $^{1,2}$, MBBS, MPH

INTRODUCTION Injury is a significant cause of mortality and morbidity. We aimed to investigate which areas in Singapore have a significantly higher incidence of road traffic accidents (RTA) resulting in severe injuries (Tier 1), which is defined as an Injury Severity Score (ISS) greater than 15, and to develop a spatiotemporal model.

METHODS Data was obtained from the National Trauma Registry. The RTA locations were geomapped onto the Singapore map, and spatial statistical techniques were used to identify hotspots with the Getis-Ord Gi* algorithm.

RESULTS From 1 January 2013 to 31 December 2014, there were 35,673 people who were injured as a result of RTAs and 976 Tier 1 RTA victims. A total of 920 people were included in the geospatial analysis. Another 56 were involved in RTAs that did not occur within Singapore or had missing location data and thus were not included. 745 (81.0\%) were discharged alive, whereas 175 (19.0\%) did not survive to discharge (median ISS 38.00, interquartile range 30.00-48.00). Most of the Tier 1 RTA victims were motorcycle riders $(50.1 \%, n=461)$, pedestrians $(21.8 \%, n=201)$ and cyclists $(9.9 \%$, $\mathrm{n}=91$ ). The majority were male and aged 20-40 years, and there was a peak occurrence at 0600-0759 hours. Nine hotspots were identified $(p<0.01)$.

CONCLUSION Information from studying hotspots of RTAs, especially those resulting in severe injuries, can be used by multiple agencies to direct resources efficiently.

Keywords: geospatial analysis, Singapore, trauma

\section{INTRODUCTION}

Injury is a significant cause of mortality and morbidity, especially in the younger population. In 2012, road traffic accidents (RTAs) were the ninth leading cause of death worldwide and are projected to be the seventh leading cause of death by the year 2030.(1) In Singapore, accidents, poisoning and violence was the top ICD-10 (International Statistical Classification of Diseases and Related Health Problems, tenth revision) diagnosis for hospitalisation for the year 2014. ${ }^{(2)}$ RTAs are the second most common mechanism of injury in those who die from trauma in Singapore, accounting for approximately $25 \%$ of all trauma deaths in 2013.(3) An international analysis of 17 high-income countries, including Singapore, showed that the social cost of RTAs ranged from a low of $0.5 \%$ to a high of $6 \%$ (average $2.7 \%$ ) of a country's gross domestic product. ${ }^{(4)}$ This economic burden is most significant, especially in the most severely injured. Even at three years post discharge, the cumulative mortality rate among RTA survivors is higher than that of the general population. ${ }^{(5)}$ Recognising road safety as a major concern, the United Nations proclaimed 2011-2020 as the decade of action for road safety and unveiled a global plan towards promoting road safety. ${ }^{(6)}$

In the 1960s, Haddon developed an approach known as the Haddon Matrix that aimed to decrease morbidity and mortality in RTAs by identifying the causative factors. ${ }^{(7)}$ This matrix examines the contributory causes of RTAs according to three phases (preevent, event and post-event) and three types of possible factors (i.e. human, vehicle and environment). This matrix provides an organised framework to (a) prevent RTAs from occurring during the pre-event phase; (b) reduce injury during the injury (event phase); and (c) lessen the impact of RTAs in the post-event phase. Knowing the hotspots, or areas where there are clusters of RTAs, can help us to more efficiently direct trauma medical service resources to improve outcomes during the post-event phase and to target primary prevention interventions during the pre-event phase. This can also enable us to examine road-user patterns from available data.

Singapore has a land area of approximately $718.3 \mathrm{sq} \mathrm{km}$ (as of June 2014) and is one of the smallest countries in the world. ${ }^{(8)}$ It had a population of 5,469,700 in 2014 and is very densely populated. ${ }^{(9)}$ There are 3,496 km of roads and $164 \mathrm{~km}$ of expressways..$^{(10)}$

Most of the severely injured (Tier 1) from RTAs are taken to the hospitals via Singapore Civil Defence Force (SCDF) ambulances. The emergency ambulance services in Singapore consist of 36 emergency ambulances and 10 private emergency ambulances, deployed from 16 fire stations islandwide. The ambulance-topopulation ratio in Singapore is 0.9:100,000. ${ }^{(11)}$ In 2011, 84.7\% of cases had an ambulance response time of within 11 minutes $^{(12)}$ from the time of dispatch till the arrival of the ambulance to the patient. A total of seven public restructured hospitals receive trauma patients from these ambulances. Singapore has an inclusive system of trauma centres, in which most acute care hospitals receive severely injured patients. All trauma patients are sent to the nearest restructured hospital, and most do not receive prehospital triage.

${ }_{1}^{1}$ Department of Emergency Medicine, Singapore General Hospital, ${ }^{2}$ Health Services and Systems Research, Duke-NUS Medical School, Singapore 
The goal of this study was to investigate which areas in Singapore have a significantly higher incidence of RTAs resulting in severe injury, which is defined as an Injury Severity Score (ISS) $>15^{(13)}$ and to develop a spatiotemporal model that describes patterns of RTAs in Singapore in order to identify potential hotspots. Using the Haddon Matrix and knowledge of the hotspot locations, we ultimately aimed to decrease the incidence of RTAs and provide better care and treatment for victims. To the best of our knowledge during the time of writing, no similar hotspot analysis of RTAs in Singapore has been published; thus, this research can potentially provide valuable information.

\section{METHODS}

Ethics approval for this study was given by the SingHealth Centralised Institutional Review Board. Data from 1 January 2013 to 31 December 2014 was obtained from the National Trauma Registry (NTR). The NTR was established in 2011 and collects nationwide data on trauma in Singapore from the SCDF, the various restructured hospitals and the Health Sciences Authority. The NTR classifies the injured according to their ISS into three tiers: Tier 1 (ISS > 15), Tier 2 (ISS 9-15 [inclusive]) and Tier 3 (ISS $<9) .{ }^{(3)}$ Demographics, outcome variables and the locations of the accidents of Tier 1 trauma patients, with RTAs as the primary mechanism of injury, were collected. Outcome variables included the final discharge status and location after discharge from the emergency department.

Geospatial and hotspot analysis have been done in other countries, ${ }^{(14-16)}$ including developing countries, via geographic information systems and Geoweb programs or Web-based geocoding tools, which are available online at low cost and are easy to use. ${ }^{(17)}$

All known locations of RTA occurrences based on NTR data were in the form of addresses. Where possible, most of the RTAs with recorded road names also had records of building landmarks nearby. The latitude and longitude coordinates of the locations were obtained by entering the addresses or road names (i.e. pin plotting) into Google Maps. ${ }^{(18)}$ These coordinates were then geomapped onto the Singapore base map via ArcGIS Desktop version 10.4 (Environmental Systems Research Institute, Redlands, CA, USA). Victims with unfilled or incompletely filled location data were excluded from the analysis. Spatial statistical techniques based on the Getis-Ord $\mathrm{Gi}^{*(19)}$ algorithm were used to identify statistically significant spatial clusters with a high incidence of RTAs resulting in severe injury (ISS > 15), thus identifying hotspots. First, location coordinates were projected using a projected coordinate system. Incident data was then aggregated using the integrate function within the collect events tool. This generated an ICOUNT field, which was a collection of weighted points rather than individual incidence points. The spatial autocorrelation tool was then used to create a graph of z-scores at each distance, and the peak was used as the distance band that reflected maximum spatial correlation for the hotspot analysis. Hotspot analysis was done, and the resultant hotspots (with their p-values) were superimposed on the base map. Each of the hotspots that was statistically significant had the individual points studied to identify if any particular road had $\geq 2$ RTAs.

The demographic data of the Tier 1 injured was analysed to characterise at-risk groups. As it was noted that the ISS might not be normally distributed in some registries, ${ }^{(20)}$ including our study population, comparisons of median ISS were done via the independent samples Mann-Whitney $U$ test or, if applicable, the independent samples Kruskal-Wallis test. All statistical analysis was done using IBM SPSS Statistics version 23.0 (IBM Corp, Armonk, NY, USA).

\section{RESULTS}

From 1 January 2013 to 31 December 2014, a total of 35,673 people were injured as a result of RTAs. There were 976 RTA victims in Tier 1 (ISS > 15), 1,431 in Tier 2 and 33,266 in Tier 3. The Tier 1 victims had a median ISS of 25.00 (interquartile range [IQR] 19.00-30.00). 56 (5.7\%) Tier 1 victims had RTAs that had not occurred within Singapore or had missing location data and thus were not included in the geospatial analysis. Out of the 920 remaining Tier 1 patients, 745 (81.0\%) were discharged alive with a median ISS of 22.00 (IQR 17.00-26.00), whereas $175(19.0 \%)$ did not survive to discharge (median ISS 38.00, IQR [30.00-48.00]). There was a statistical difference between the median ISS of those who survived to discharge and that of those who died $(\mathrm{p} \leq 0.001)$.

The characteristics of the 920 victims are shown in Table I. Most of the survivors were discharged home, with many being transferred to a rehabilitation facility. The majority of the Tier 1 RTA victims were motorcycle riders $(50.1 \%, \mathrm{n}=461)$, pedestrians $(21.8 \%, \mathrm{n}=201)$ and cyclists $(9.9 \%, \mathrm{n}=91)$. There was, however, no statistical difference in median ISS between the different injury mechanisms $(p=0.206)$. Most of the Tier 1 RTAs occurred between 0600 hours and 0959 hours, with a second peak between 1800 hours and 1959 hours. For 106 Tier 1 RTA victims, the time of the incident had not been documented in their records, and the NTR data was not able to capture this information. Most of the severely injured Tier 1 victims were young, aged 20-29 years $(\mathrm{n}=209)$ and $30-39$ years $(\mathrm{n}=174)$.

After geomapping all 920 coordinates of RTA locations that had $\geq 1$ person with severe injuries, nine statistically significant hotspots were generated. All hotspots had a confidence level greater than 99\% ( $<$ < 0.01) (Fig. 1 \& Table II).

The hotspots were studied for location and geographic proximity. There was a distinct cluster of hotspots around the Woodlands area (Fig. 1 \& Appendix, Supplementary Fig. 1). One possible contributing factor was the large amount of motorbike traffic transiting the area on the way to and from the causeway with Malaysia, which is situated nearby. The other hotspots were at major road intersections (Appendix, Supplementary Fig. 2), expressways (Appendix, Supplementary Figs. 3 \& 4), outside the Institute of Mental Health (Appendix, Supplementary Fig. 5) and at Geylang Road, which is known to have a high amount of pedestrian sidewalk and vehicular traffic (Appendix, Supplementary Fig. 6). Most of the Tier 1 victims were motorcycle riders and pedestrians, with the exception 
Table I. Description of Tier 1 victims $(n=920)$.

\begin{tabular}{|c|c|}
\hline Characteristic & No. (\%) \\
\hline \multicolumn{2}{|l|}{ Age (yr) } \\
\hline $0-9$ & 13 \\
\hline $10-19$ & 32 \\
\hline $20-29$ & 209 \\
\hline $30-39$ & 174 \\
\hline $40-49$ & 146 \\
\hline $50-59$ & 123 \\
\hline $60-69$ & 120 \\
\hline $70+$ & 103 \\
\hline \multicolumn{2}{|l|}{ Discharge location } \\
\hline Morgue/mortuary & $159(17.3)$ \\
\hline Home & $517(56.2)$ \\
\hline Nursing home & $21(2.3)$ \\
\hline Others & $10(1.1)$ \\
\hline Repatriated & $8(0.9)$ \\
\hline Transferred to another acute hospital & $49(5.3)$ \\
\hline Transferred to rehabilitation facility & $115(12.5)$ \\
\hline Discharged against medical advice/at own risk & $23(2.5)$ \\
\hline Unknown or missing data & $18(2.0)$ \\
\hline \multicolumn{2}{|l|}{ Injured person } \\
\hline Cyclist (not vs. vehicle) & $16(1.7)$ \\
\hline Cyclist (vs. vehicle) & $75(8.2)$ \\
\hline Motor vehicle back passenger & $40(4.3)$ \\
\hline Motor vehicle driver & $72(7.8)$ \\
\hline Motor vehicle front passenger & $16(1.7)$ \\
\hline Motorbike pillion & $26(2.8)$ \\
\hline Motorbike rider & $461(50.1)$ \\
\hline Others & $3(0.3)$ \\
\hline Pedestrian & $201(21.8)$ \\
\hline Unknown or missing data & $10(1.1)$ \\
\hline \multicolumn{2}{|l|}{ Time of injury } \\
\hline 0000-0159 & 48 \\
\hline 0200-0359 & 35 \\
\hline 0400-0559 & 43 \\
\hline 0600-0759 & 122 \\
\hline 0800-0959 & 98 \\
\hline $1000-1159$ & 45 \\
\hline $1200-1359$ & 55 \\
\hline $1400-1559$ & 65 \\
\hline $1600-1759$ & 67 \\
\hline $1800-1959$ & 91 \\
\hline $2000-2159$ & 78 \\
\hline $2200-2359$ & 67 \\
\hline Unknown & 106 \\
\hline
\end{tabular}

of the victims at Geylang Road, who consisted solely of pedestrians.

\section{DISCUSSION}

In this study, the injured RTA victims in Tier 1 tended to be young, male and from the most economically productive age group.
One reason for this finding could be the higher risk appetite of road users in this group. This reflects global trends ${ }^{(1,21-24)}$ and further illustrates the burden of injury as a disease. It should also be recognised that the elderly are particularly susceptible to RTAs, possibly due to impaired judgement, reduced reflexes and mobility. This elderly group will become more significant as Singapore, like many other developed countries, experiences a greying population. ${ }^{(25)}$ As such, traffic safety measures and policies, together with any changes in the trauma system, must take this group into consideration.

As expected, the injured who did not survive to discharge from hospital had a higher median ISS compared to the survivors. Notably, there were two peak timings for RTAs with Tier 1 victims, between 0600 hours and 0959 hours as well as between 1800 hours and 1959 hours. This is likely due to peak hour traffic with a large number of motorists and pedestrians going to their workplaces or returning home.

The World Health Organization's Global Status Report on Road Safety 2015 noted that almost half of the deaths on the road were among motorcyclist, cyclists and pedestrians, ${ }^{(26)}$ who are known to be 'vulnerable' road users. Similarly, in Singapore, most of the Tier 1 injured belonged to this 'vulnerable' group. Furthermore, it was interesting to note that Geylang Road had a disproportionately high incidence of pedestrians becoming severely injured. This particular road should be studied in further detail and protective measures instituted for pedestrians.

Legislation can help to decrease the incidence of RTAs, mainly as a form of deterrence. Although Singapore has strict laws regarding speeding, drunk driving, seatbelts, helmets and child restraints, enforcement can be enhanced with the help of the traffic police along the roads and areas that correspond to the hotspots. This may help to mitigate the human factors in the pre-event and event phases of Haddon's Matrix. Road safety specialists from the Land Transport Authority can help to investigate and introduce ways to improve the environmental factors for the pre-event and event phases to promote road safety along the roads of concern. Road signs warning of high-risk areas may help increase awareness and caution among motorists and pedestrians.

Education plays a crucial role in addressing human factors in all phases of the Haddon Matrix. Incorporating the concept of road safety into school curriculum for children can create road safety awareness, correct attitudes and encourage appropriate behaviour on the roads. The mainstream media in Singapore can also play a greater role in public education on trauma and RTAs. ${ }^{(27)}$ Social media has, in recent years, begun to emerge as a powerful tool in education and generating public interest, and its importance cannot be ignored.

A good knowledge of where the hotspots are can guide efforts to decrease both the response time of SCDF ambulances and the time taken to transport the injured to a trauma centre. Despatch centres could be located near these hotspots and be adequately staffed and allocated with optimal prehospital medical resources. The quicker the response of the ambulances, the sooner the patient can arrive at the trauma centre where time-sensitive and 
Table II. Hotspot data.

\begin{tabular}{|c|c|c|c|c|c|c|}
\hline Hotspot & GiZscore & GiZscore p-value & X-coordinate & Y-coordinate & ICOUNT & Type \\
\hline 1 & 3.967136 & $7.27 e-05$ & 103.7703 & 1.443346 & 3 & Motorbike rider \\
\hline 1 & 3.967136 & $7.27 e-05$ & 103.7705 & 1.443275 & 3 & Motorbike rider \\
\hline 1 & 3.967136 & 7.27e-05 & 103.7704 & 1.443352 & 3 & Motorbike rider \\
\hline 2 & 3.96714 & 7.27e-05 & 103.639 & 1.330567 & 3 & Motorbike rider \\
\hline 2 & 3.96714 & 7.27e-05 & 103.6391 & 1.331081 & 3 & Motorbike rider \\
\hline 2 & 3.96714 & $7.27 e-05$ & 103.6391 & 1.331081 & 3 & Motorbike rider \\
\hline 3 & 3.967141 & $7.27 e-05$ & 103.9318 & 1.375742 & 3 & Motorbike rider \\
\hline 3 & 3.967141 & $7.27 e-05$ & 103.9319 & 1.375779 & 3 & Motorbike rider \\
\hline 3 & 3.967141 & $7.27 e-05$ & 103.9325 & 1.375382 & 3 & Motor vehicle driver \\
\hline 4 & 3.967141 & $7.27 e-05$ & 103.8845 & 1.379353 & 3 & Motorbike pillion \\
\hline 4 & 3.967141 & 7.27e-05 & 103.8845 & 1.379353 & 3 & Motorbike rider \\
\hline 4 & 3.967141 & 7.27e-05 & 103.8845 & 1.380068 & 3 & Motorbike rider \\
\hline 5 & 3.967149 & 7.27e-05 & 103.8088 & 1.336892 & 3 & Motorbike rider \\
\hline 5 & 3.967149 & $7.27 e-05$ & 103.8086 & 1.337208 & 3 & Pedestrian \\
\hline 5 & 3.967149 & $7.27 e-05$ & 103.8085 & 1.337251 & 3 & Motorbike rider \\
\hline 6 & 3.967173 & $7.27 e-05$ & 103.7687 & 1.432567 & 3 & Motorbike rider \\
\hline 6 & 3.967173 & $7.27 e-05$ & 103.7687 & 1.433014 & 3 & Motorbike rider \\
\hline 6 & 3.967173 & 7.27e-05 & 103.7687 & 1.432816 & 3 & Motorbike rider \\
\hline 7 & 3.967214 & 7.27e-05 & 103.8791 & 1.31158 & 3 & Pedestrian \\
\hline 7 & 3.967214 & $7.27 e-05$ & 103.879 & 1.312528 & 3 & Pedestrian \\
\hline 7 & 3.967214 & $7.27 e-05$ & 103.8799 & 1.312667 & 3 & Pedestrian \\
\hline 8 & 6.158884 & $7.30 \mathrm{e}-10$ & 103.8035 & 1.432228 & 4 & Motor vehicle driver \\
\hline 8 & 6.158884 & $7.30 \mathrm{e}-10$ & 103.8035 & 1.432228 & 4 & Motor vehicle front passenger \\
\hline 8 & 6.158884 & $7.30 \mathrm{e}-10$ & 103.8029 & 1.432754 & 4 & Motorbike rider \\
\hline 8 & 6.158884 & $7.30 \mathrm{e}-10$ & 103.8035 & 1.432277 & 4 & Motor vehicle driver \\
\hline 9 & 6.15892 & $7.30 \mathrm{e}-10$ & 103.7701 & 1.427733 & 4 & Motorbike rider \\
\hline 9 & 6.15892 & $7.30 \mathrm{e}-10$ & 103.7701 & 1.427737 & 4 & Motorbike pillion \\
\hline 9 & 6.15892 & $7.30 \mathrm{e}-10$ & 103.7701 & 1.427783 & 4 & Motorbike rider \\
\hline 9 & 6.15892 & $7.30 \mathrm{e}-10$ & 103.7702 & 1.427668 & 4 & Motorbike rider \\
\hline
\end{tabular}

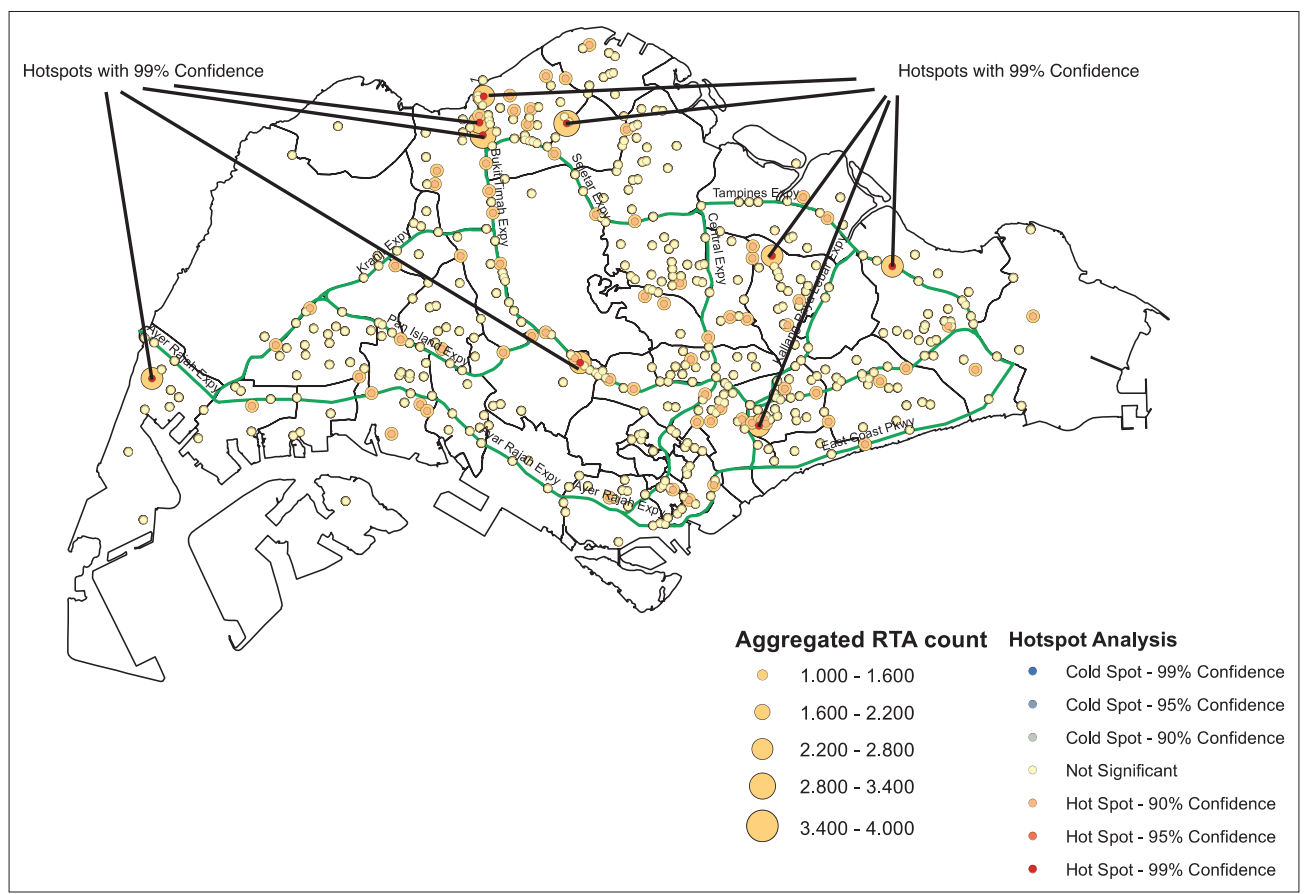

Fig. 1 Diagram shows hotspots of road traffic accidents (RTAs) in Singapore. 
potentially life-saving procedures can be performed. On a similar note, the hospitals or trauma centres that receive major trauma cases should also take these hotspots into account and allocate resources accordingly. Based on the location of the hospitals in Singapore and their proximity to the hotspots, Khoo Teck Puat Hospital is likely to receive many Tier 1 RTA victims.

There were some limitations to the study. Only the Tier 1 injured were studied and analysed. This may not give a complete picture, and it is debatable whether the results can be generalised to all RTAs in Singapore. However, it is also likely that Tier 1 patients are a surrogate for patients in the lower tiers, and since Tier 1 patients tend to have higher impact in terms of socioeconomic burden and resource demand, it may be more crucial to focus efforts on this group. Furthermore, Tier 1 patients were selected for the study because their data integrity was better, and they required more resources and had higher mortality and morbidity. Additionally, the study mainly examined Tier 1 RTA victims and not the RTA itself as an event. However, it is unlikely that this would have made a significant difference to the analysis, as our data analysis showed that there were only five RTAs in 2013 that had more than one Tier 1 victim, all of which had only two Tier 1 victims. Another limitation of hotspot analysis for RTAs is that hotspots are determined via distance and do not take into account how roads run (i.e. hotspots are purely directional, whereas roads can be linear, circular or zigzag). Thus, it may not be apparent which roads have a high incidence rate of RTAs based on the hotspots alone.

During the study, we noted that information on the location of the RTAs was not as complete as expected. Although the location data was complete in $88.4 \%$ of the victims, the completion rate of the location data was much lower in the lower tiers. Although the Singapore Traffic Police may collect accurate information on the locations of RTAs, this information is not shared by the police nor collected by the NTR. The Traffic Police also does not have data on the outcomes of the victims or information on the severity of the injuries sustained. One assumption made in this study was that the severely injured would not have been moved from the location of the RTA and, thus, the location where the victim was picked up as recorded by the SCDF paramedics would likely be the site of the RTA. However, it would be ideal if we could match and analyse the location data collected by the Traffic Police with patient injury and outcome data from the NTR.

To our knowledge, this study is the first in Singapore that aimed to provide information regarding the geospatial distribution and relationship of RTAs with Tier 1 victims. This information can guide and focus the efforts of the relevant authorities to ensure effective and efficient use of resources. Considering the importance of keeping and using accurate location records, direct recording of the location of RTA incidents can be done via Global Positioning System devices. A geodatabase can then be set up, and any data collected submitted to the NTR. The methodology and framework used in this study can be applied to a larger-scale future study involving all tiers of RTAs or other forms of trauma such as falls. To take this even further, similar geospatial analysis can be done for other medical conditions that require resources from multiple agencies, such as out-of-hospital cardiac arrests.

In conclusion, road safety, prevention of RTAs, treatment and eventual rehabilitation of RTA victims require much coordinated effort from multiple agencies. Law enforcement, land and road safety professionals, prehospital EAS, trauma centres, and rehabilitation facilities are all important links in this chain. Through the study of hotspots of traumatic events, especially those resulting in severe injuries, information can be collected and used by multiple agencies to direct their efforts and resources. Based on our study findings, we recommend that preventive measures be employed along the Bukit Timah Expressway just north of the Seletar Expressway, as there are three hotspots there. Similarly, Geylang Road should have preventive measures in place, given the higher incidence of severely injured pedestrians. Khoo Teck Puat Hospital would be the receiving hospital for many of the hotspots if we continue using an inclusive trauma system. A good geodatabase can help other similar studies to better understand the trauma from road traffic accidents in Singapore.

\section{SUPPLEMENTARY MATERIAL}

The Appendix is available online at https://doi.org/10.11622/ smedj.2020037.

\section{REFERENCES}

1. World Health Organization. Violence and Injury Prevention: Injuries and violence: the facts 2014. Available at: https://www.who.int/violence_injury prevention/media/news/2015/Injury_violence_facts_2014/en/. Accessed March 28, 2015.

2. Ministry of Health Singapore. Top 10 conditions of hospitalisation. Available at: https://www.moh.gov.sg/content/moh_web/home/statistics/Health_Facts_ Singapore/Top_10_Conditions_of_Hospitalisation.html. Accessed March 28, 2015.

3. National Registry of Diseases Office, Singapore. National Trauma Registry Annual Registry Report 2012-2013. Singapore: Health Promotion Board, 2014.

4. Wijnen W, Stipdonk H. Social costs of road crashes: an international analysis. Accid Anal Prev 2016; 94:97-106.

5. Davidson GH, Hamlat CA, Rivara FP, et al. Long-term survival of adult trauma patients. JAMA 2011; 305:1001-7.

6. World Health Organization. Global Plan for the Decade of Action for Road Safety 2011-2020. Geneva: World Health Organization, 2009.

7. Haddon W Jr. The changing approach to the epidemiology, prevention, and amelioration of trauma: the transition to approaches etiologically rather than descriptively based. 1968. Inj Prev 1999; 5:231-5.

8. Ministry of Trade \& Industry. Yearbook of Statistics Singapore 2015. Singapore: Department of Statistics, Ministry of Trade \& Industry, 2015.

9. Ministry of Trade \& Industry. Population Trends 2014. Singapore: Ministry of Trade \& Industry, 2014.

10. Land Transport Authority. Singapore Land Transport Statistics in Brief 2015. Available at: https://www.Ita.gov.sg/content/dam/ltaweb/corp/ PublicationsResearch/files/FactsandFigures/Statistics\%20in \%20Brief\%20 2015\%20FINAL.pdf. Accessed March 28, 2015.

11. Shin SD, Ong ME, Tanaka H, et al. Comparison of emergency medical services systems across Pan-Asian countries: a Web-based survey. Prehosp Emerg Care 2012; 16:477-96. [Epub ahead of print]

12. Williams L, Lim M. Singapore Civil Defence Force Annual Report 2014. Singapore: Singapore Civil Defence Force, 2014.

13. Baker SP, O'Neill B, Haddon W Jr, Long WB. The injury severity score: a method for describing patients with multiple injuries and evaluating emergency care. J Trauma 1974; 14:187-96.

14. Jansen JO, Morrison JJ, Wang $\mathrm{H}$, et al. Optimizing trauma system design: the GEOS (Geospatial Evaluation of Systems of Trauma Care) approach. J Trauma Acute Care Surg 2014; 76:1035-40.

15. Slaughter DR, Williams N, Wall SP, et al. A community traffic safety analysis of pedestrian and bicyclist injuries based on the catchment area of a trauma center. J Trauma Acute Care Surg 2014; 76:1103-10.

16. Newgard CD, Schmicker RH, Sopko G, et al; Resuscitation Outcomes Consortium Investigators. Trauma in the neighborhood: a geospatial analysis 
and assessment of social determinants of major injury in North America. Am Public Health 2011; 101:669-77.

17. Cinnamon J, Schuurman N. Injury surveillance in low-resource settings using Geospatial and Social Web technologies. Int J Health Geogr 2010; 9:25.

18. Google Maps. Map of Singapore. Available at: https://www.google.com.sg/ma ps/@1.3437459,103.8240449,11z. Accessed March 20, 2015.

19. Getis A, Ord JK. The analysis of spatial association by use of distance statistics. Geographical Analysis 1992; 24:189-206.

20. Stevenson M, Segui-Gomez M, Lescohier I, Di Scala C, McDonald-Smith G. An overview of the injury severity score and the new injury severity score. In Prev 2001; 7:10-3.

21. American College of Surgeons. National Trauma Data Bank 2014 Annual Report. Available at: https://www.facs.org/ /media/files/quality\%20programs/trauma/ ntdb/ntdb\%20annual\%20report\%202014.ashx. Accessed March 28, 2015.

22. Bouaoun L, Haddak MM, Amoros E. Road crash fatality rates in France: a comparison of road user types, taking account of travel practices. Accid Anal Prev 2015; 75:217-25.
23. Seid M, Azazh A, Enquselassie F, Yisma E. Injury characteristics and outcome of road traffic accident among victims at Adult Emergency Department of Tikur Anbessa specialized hospital, Addis Ababa, Ethiopia: a prospective hospital based study. BMC Emerg Med 2015; 15:10.

24. Rus Ma D, Peek-Asa C, Baragan EA, Chereches RM, Mocean F. Epidemiology of road traffic injuries treated in a large Romanian emergency department in Tîrgu-Mureş between 2009 and 2010. Traffic Inj Prev 2015; 16:835-41.

25. Wong TH, Nadkarni NV, Nguyen HV, et al. One-year and three-year mortality prediction in adult major blunt trauma survivors: a national retrospective cohort analysis. Scand J Trauma Resusc Emerg Med 2018; 26:28.

26. World Health Organization. Global Status Report on Road Safety 2015. Available at: https://www.who.int/violence_injury_prevention/road_safety_status/2015/ status_report2015/en/. Accessed March 27, 2015.

27. Heng KW, Vasu A. Newspaper media reporting of motor vehicle crashes in Singapore: an opportunity lost for injury prevention education? Eur J Emerg Med 2010; 17:173-6. 


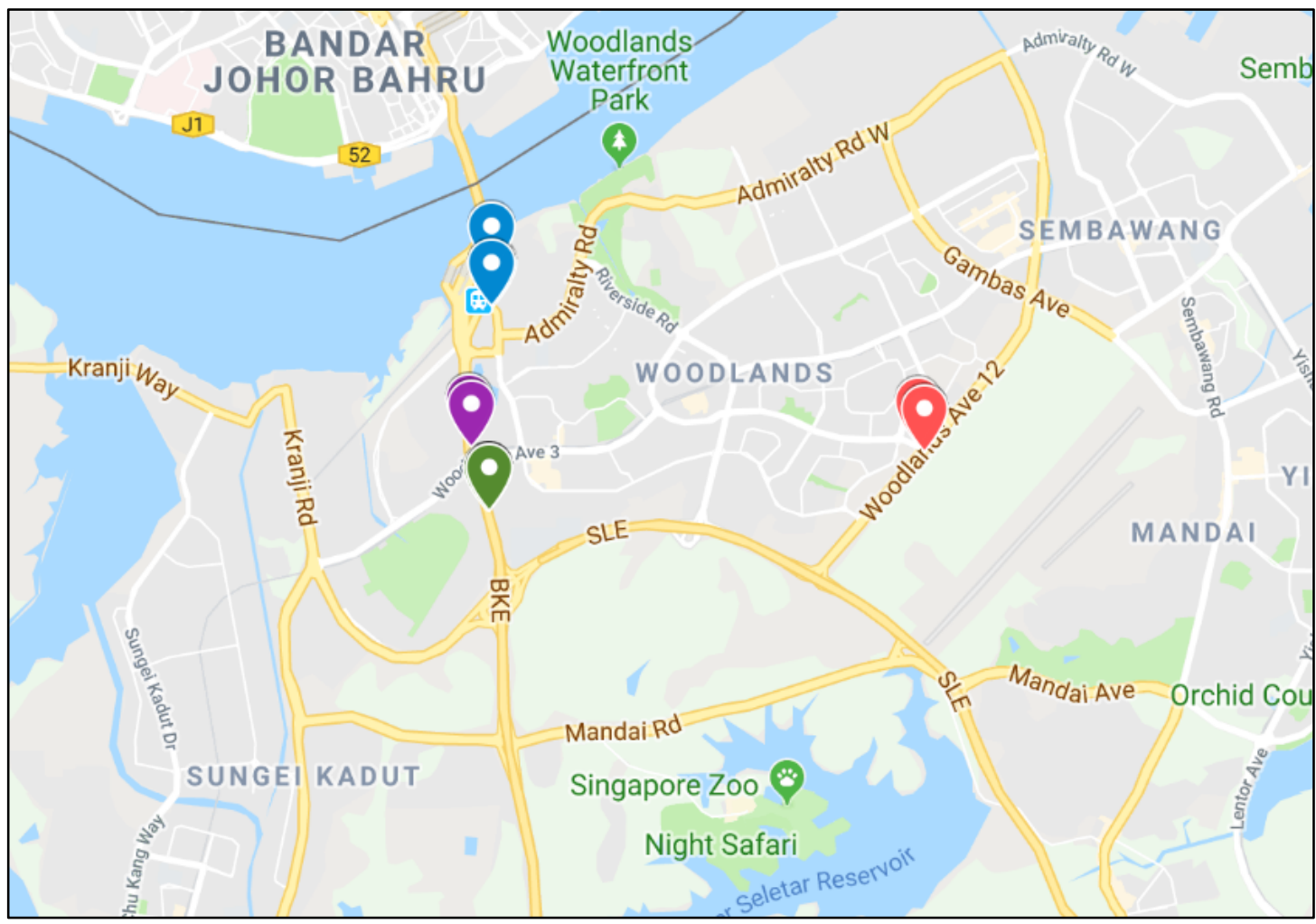

Supplementary Fig. 1 Image shows Hotspots 1, 5, 8 and 9 in the Woodlands cluster. (Map data $\odot 2016$ Google)

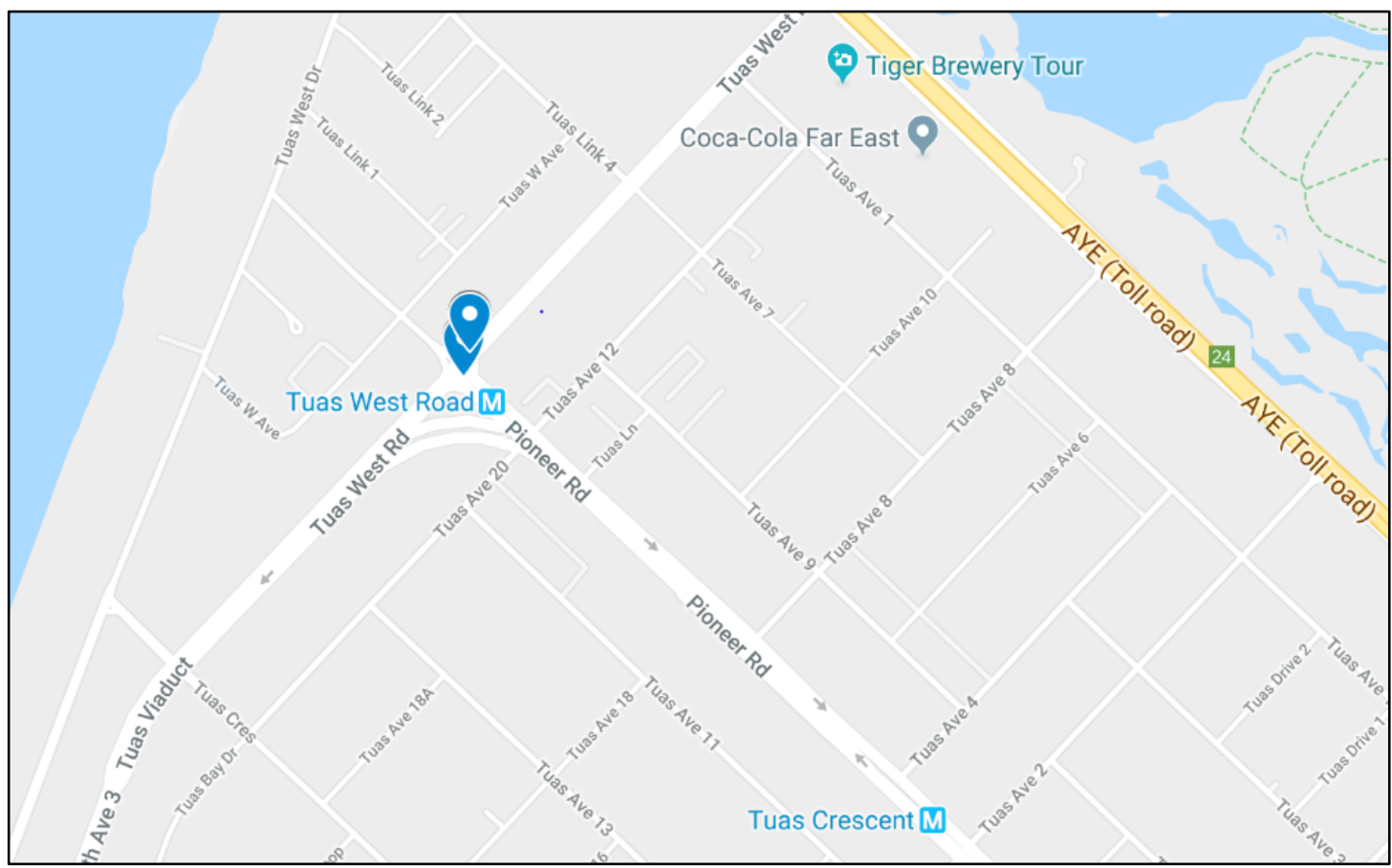

Supplementary Fig. 2 Image shows Hotspot 2 at the intersection of Tuas West Road and Pioneer Road. (Map data $\odot 2016$ Google) 


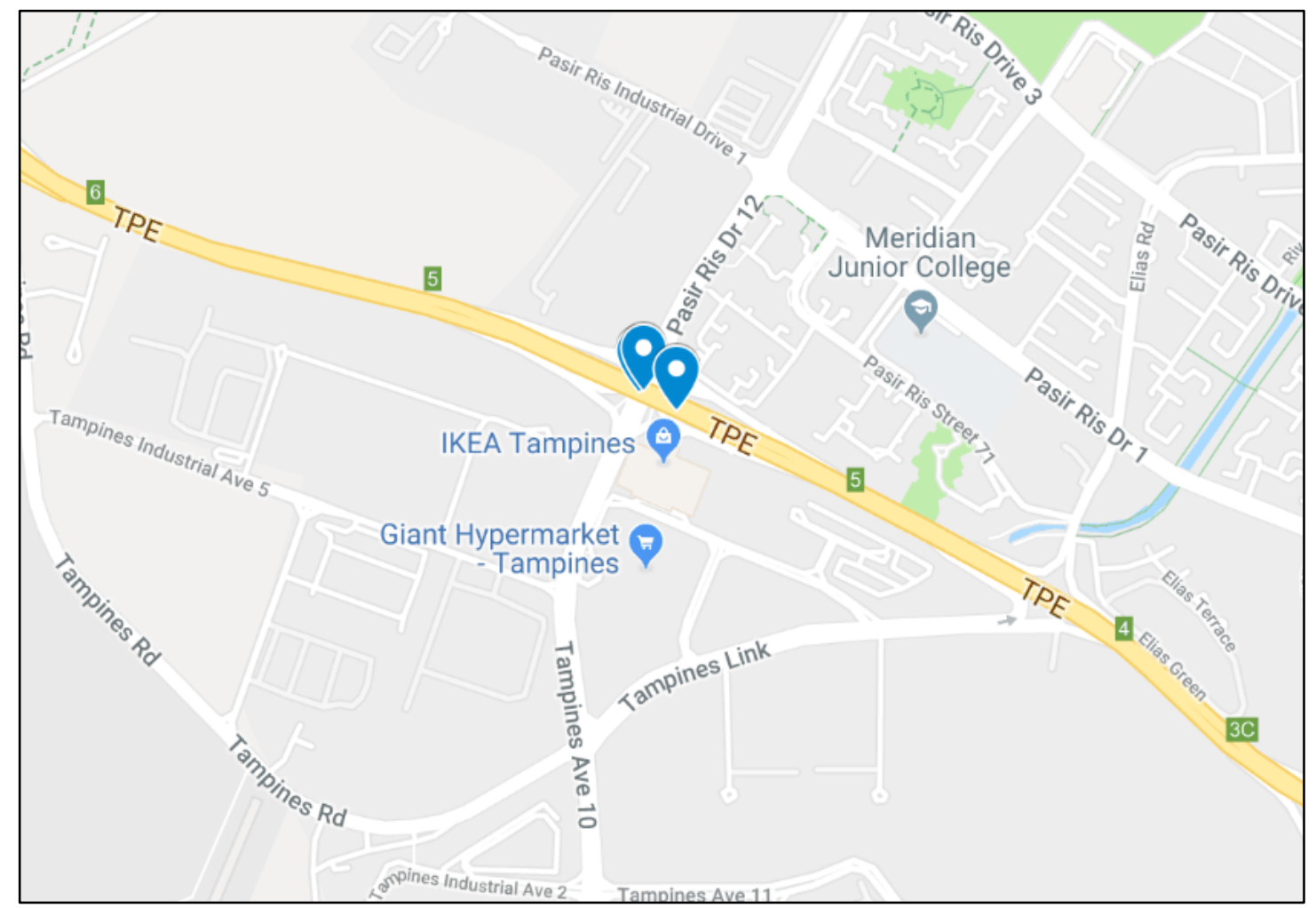

Supplementary Fig. 3 Image shows Hotspot 3 along the Tampines Expressway. (Map data $\odot 2016$ Google)

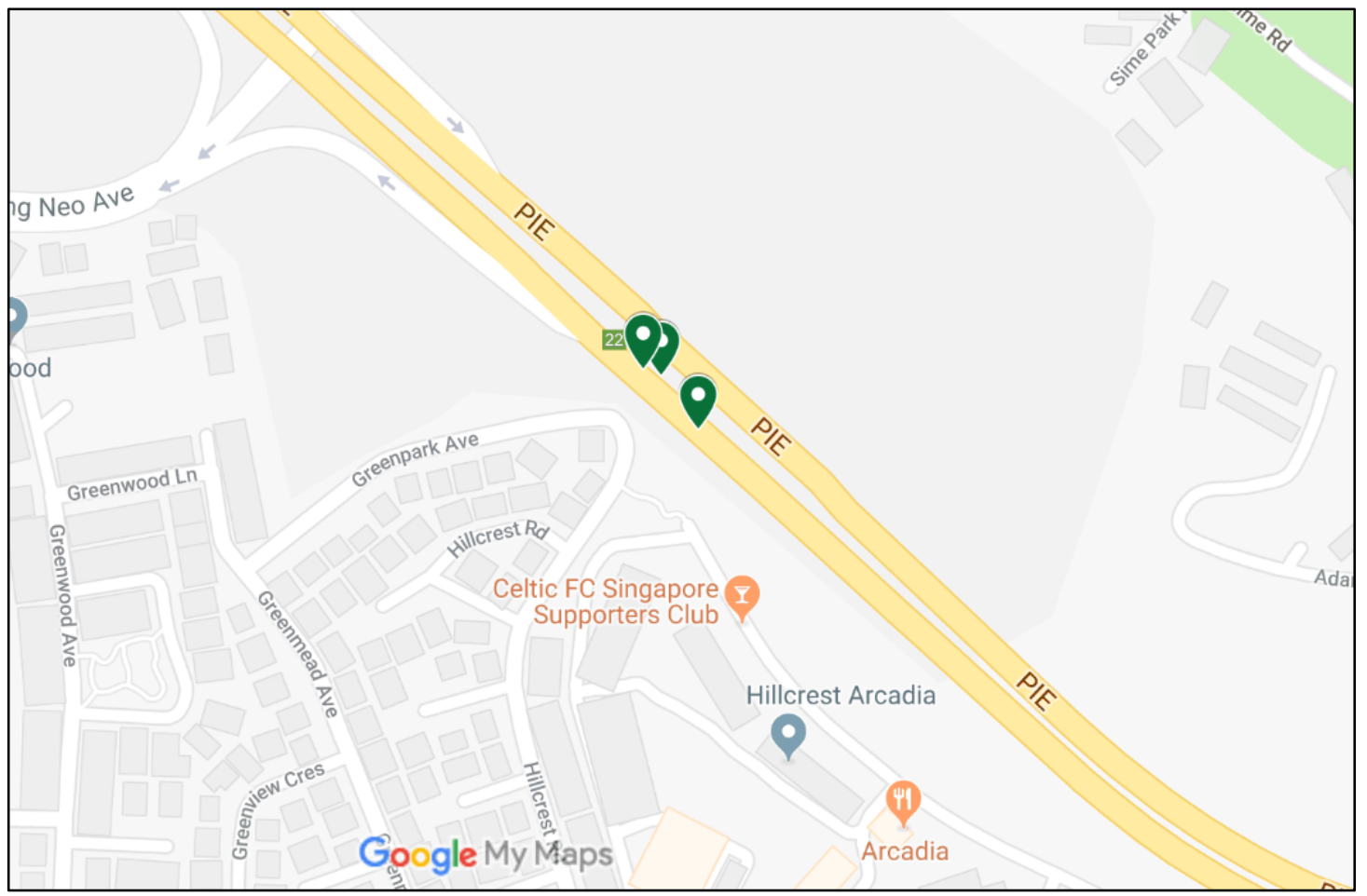

Supplementary Fig. 4 Image shows Hotspot 6 along the Pan Island Expressway. (Map data $\odot 2016$ Google) 


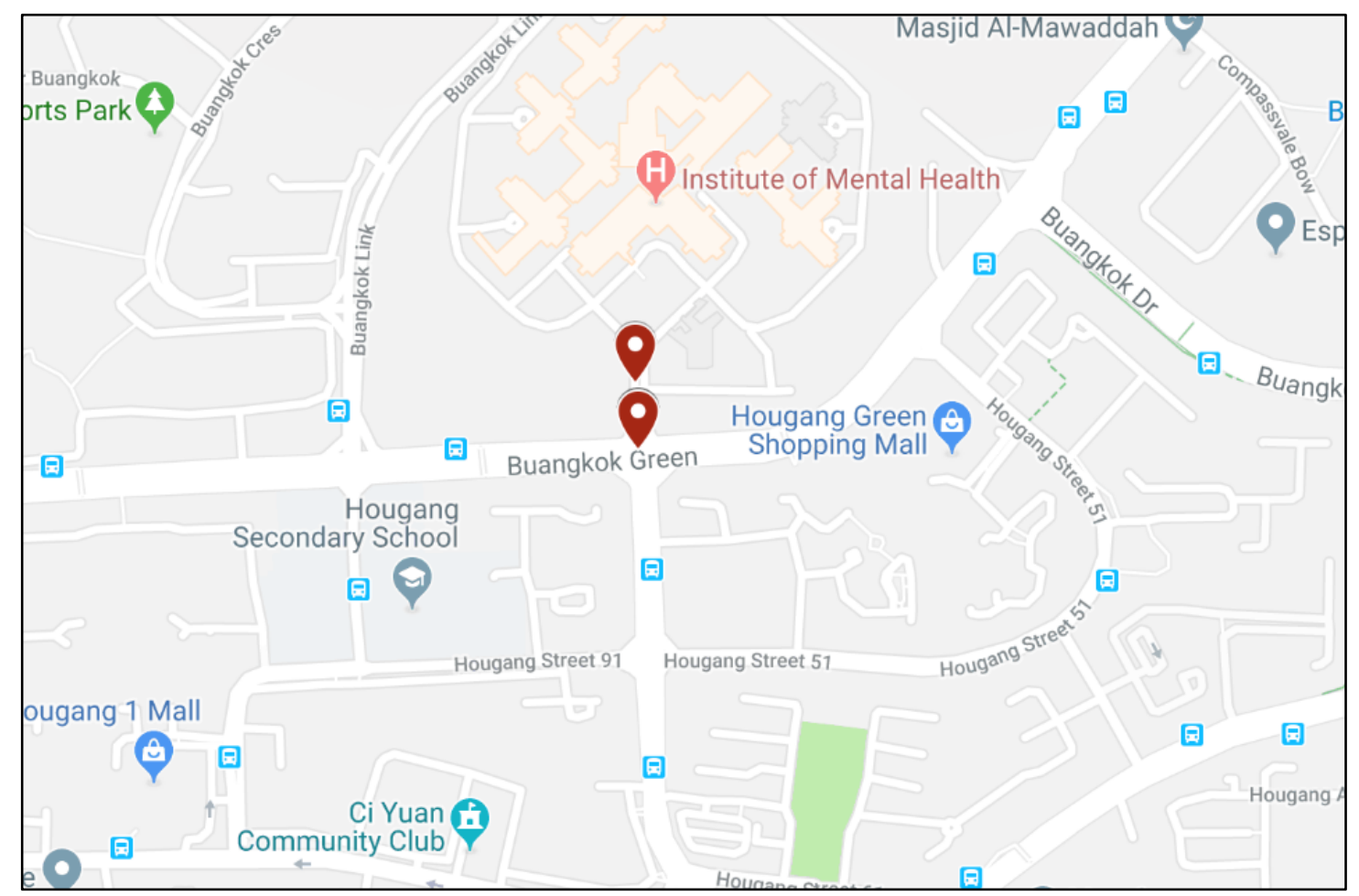

Supplementary Fig. 5 Image shows Hotspot 4 off Buangkok Green. (Map data $\odot 2016$ Google)

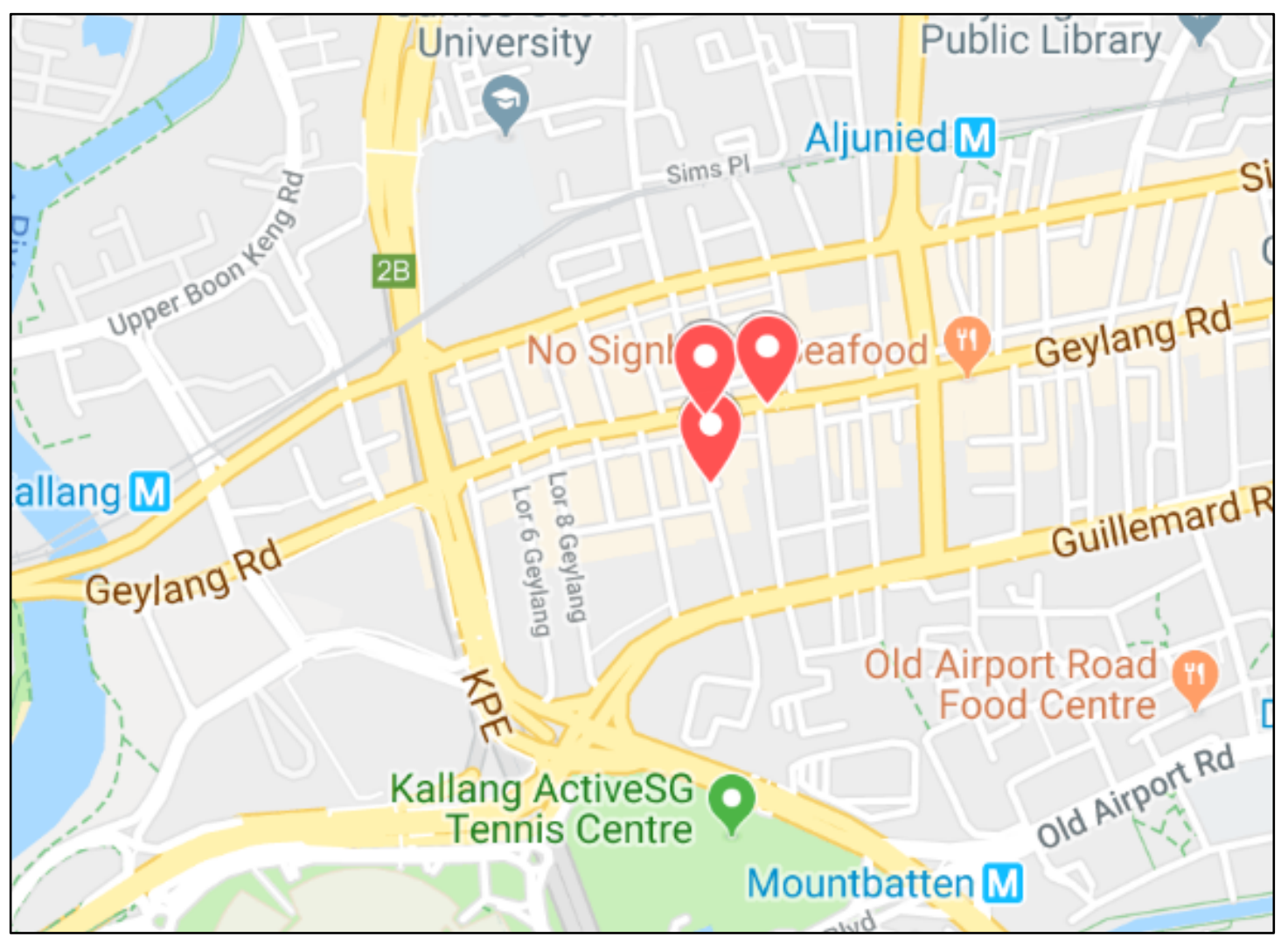

Supplementary Fig. 6 Image shows Hotspot 7 near Geylang Road. (Map data $\odot 2016$ Google) 